\title{
Age and depth of oceanic slab- derived diamonds and the formation of Archean subcontinental mantle
}

\author{
STEVEN B. ShIREY ${ }^{1 *}$ AND KAREN V. SMiT ${ }^{2}$ \\ $1 *$ Carnegie Science Earth and Planets Laboratory, \\ Washington, DC 20015 (sshirey@carnegiescience.edu) \\ ${ }^{2}$ Gemological Institute of America, 50 West 47th Street, New \\ York, NY 10036 (ksmit@gia.edu)
}

The Precambrian is marked by the stabilization of subcontinental mantle lithosphere and associated crystallization of lithospheric diamonds from slab-derived carbon [1,2]. These features and higher nitrogen contents are consistent with diamond fluid delivery from the crustal (eclogitic) part of the slab and keel growth by lateral accretion/advective thickening [e.g. 3-5] in shallow and reducing mantle wedge settings. Such diamonds are rare to non-existent in the Phanerozoic.

Sublithospheric diamonds are also slab-derived but from nitrogen-poor fluids/melts. These diamond fluids were delivered from deeper carbonated crustal or serpentinized mantle portions of cold slabs that subducted into the mantle transition zone regions and warmed up. While the age of such sublithospheric diamonds is poorly known, current mantle tomogrpahy shows that these conditions are a feature of the modern Earth and are consistent with the few ages that show these diamonds are younger. Aside from depth differences, the conditions for the crystallization of slab-associated lithospheric vs sublithospheric diamonds are fundamentally different in slab temperature, fluid composition, and fluid source within the slab source-rock.

We hypothesize that these differences between lithospheric and sublithospheric diamonds may also be of temporal significance. If so, slab-derived diamond petrogenesis could be a key to understanding why cratonic keel formation is prevalent in the early Precambrian. Slabderived diamonds provide evidence for a transition from Precambrian conditions of shallow-devolatilization and warmer, more buoyant plates, that would facilitate lithosphere thickening to Phanerozoic conditions of deeperdevolatilization, cooler, and less buoyant plates, that are less conducive to lithosphere thickening.

[1] Shirey and Richardson, Science 333 434-436 (2011). [2] Howell et al., GCA (in press, 2020). [3] Jordan, Journal Petrology, Spec. Lithosphere Issue 11-37 (1978). [4] Smit et al., Science 364 383-395 (2019). [5] Scott et al., EPSL 507 175-186 (2019). 